Bài báo khoa học

\title{
Thị trường trao đổi tín chỉ các-bon: Kinh nghiệm quốc tế và chính sách cho Việt Nam
}

\author{
Mai Kim Liên ${ }^{1}$, Lương Quang Huy ${ }^{1}$, Nguyễn Thành Công ${ }^{1 *}$, Đỗ Tiến Anh ${ }^{2}$ \\ ${ }^{1}$ Cục Biến đổi khí hậu; lien_va21@yahoo.com, huylq98@gmail.com, \\ tcongnguyen90@gmail.com \\ ${ }^{2}$ Tổng cục Khí tượng Thủy văn; atdo1980@gmail.com \\ * Tác giả liên hệ: tcongnguyen90@gmail.com; Tel.: +84-829906696
}

Ban Biên tập nhận bài: 12/9/2020; Ngày phản biện xong: 02/11/2020; Ngày đăng bài: $25 / 11 / 2020$

Tóm tắt: Việt Nam coi ứng phó với biến đổi khí hậu là vấn đề có ý nghĩa sống còn. Úng phó với biến đổi khí hậu của Việt $\mathrm{Nam}$ phải gắn liền với phát triển bền vững, hướng tới nền kinh tế các-bon thấp. Theo đó, trong Đóng góp do quốc gia tự quyết định (NDC), Việt Nam cam kết bằng nguồn lực trong nước, đến năm 2030 sẽ giảm $9 \%$ tổng lượng phát thải khí nhà kính so với Kịch bản phát triển thông thường (BAU) quốc gia, tập trung vào 5 lĩnh vực chính bao gồm: năng lượng; các quá trình công nghiệp; nông nghiệp; sử dụng đất thay đổi sử dụng đất và lâm nghiệp (LULUCF); chất thải. Mức cam kết này có thể tăng lên tới $27 \%$ nếu nhận được sự hỗ trợ từ phía quốc tế thông qua hợp tác song phương, đa phương và các cơ chế thị trường theo Thỏa thuận Paris về biến đổi khí hậu. Song song với các nỗ lực giảm nhẹ, Chính phủ Việt Nam cũng đặt ưu tiên trong việc duy trì đà phát triển kinh tế xã hội. Trong bối cảnh như vậy, việc xây dựng và thiết lập thị trường các-bon nội địa phù hợp với các điều kiện kinh tế, chính trị, xã hội của Việt Nam là phù hợp và thiết thực. Tuy nhiên, để có thể hỗ trợ Việt Nam trong xây dựng thị trường các-bon nội địa, trước hết cần nghiên cứu các kinh nghiệm quốc tế trong việc thiết lập và xây dựng thị trường các-bon nội địa, cần phải hiểu được hoàn cảnh ra đời của các thị trường, mục tiêu và cách thức hoạt động của các thị trường này. Thị trường các-bon nội địa của các nước khác nhau có những đặc thù khác nhau, thị trường các-bon nội địa của các nước phát triển khác với các nước đang phát triển. Dựa trên tổng hợp kinh nghiệm quốc tế, phân tích hiện trạng hạ tầng thể chế, chính sách ở Việt Nam, bài báo đề xuất các giải pháp cụ thể để hướng tới xây dựng và triển khai thành công thị trường trao đổi tín các-bon nội địa cho Việt Nam.

Từ khóa: Thị trường các-bon nội địa; Đóng góp do quốc gia tự quyết định; ETS.

\section{Giới thiệu về thị trường trao đổi tín chỉ các-bon}

Trong những năm gần đây, ảnh hưởng của biến đổi khí hậu, sự suy thoái của môi trường sống đã không chỉ tác động tiêu cực đến chất lượng cuộc sống của người dân, mà có ảnh hưởng nghiêm trọng đến sự phát triển bền vững của quốc gia, khu vực và thế giới. Nhằm giải quyết các vẩn đề liên quan đến biến đổi khí hậu, Liên Hiệp Quốc đã tổ chức nhiều Hội nghị về biến đổi khí hậu để tìm ra các phương án hiệu quả và thiết thực nhất. Theo đó, trao đổi các-bon được coi là một trong những công cụ quan trọng nhất trong việc giảm nhẹ phát thải khí nhà kính [1]. Thông qua cơ chế thị trường (thị trường trao đổi tín chỉ các-bon), các bên tham gia có thể tăng cường giảm nhẹ phát thải khí nhà kính một cách hiệu quả và tiết kiệm. Nguyên tắc cơ bản của thị trường trao đồi tín chỉ các-bon (thị trường các-bon) là bên phát thải lớn sẽ trả phí để nhận thêm các tín chỉ, hạn ngạch phát thải nhằm đạt được các mục tiêu giảm nhẹ. Tính đến năm 2019 , quy mô của thị trường các-bon trên toàn thế giới rơi vào khoảng 45 tỷ Đô la Mỹ [2]. Trên thực 
tế, thị trường các-bon trên thế giới tồn tại dưới hai hình thức: (i) thị trường các-bon bắt buộc và (ii) thị trường các-bon tự nguyện. Thị trường các-bon bắt buộc được thành lập và quản lý bởi các hiệp định, thỏa thuận giảm phát thải các-bon quốc gia và quốc tế, ví dụ như Nghị định thư Kyoto, thị trường trao đổi phát thải của Liên minh châu Âu. Cơ chế vận hành tiêu biểu cho thị trường các-bon bắt buộc là thông qua thiết lập hệ thống thương mại phát thải (Emission Trading Scheme-ETS). Cụ thể, chính phủ có nhiệm vụ phân bổ, hoặc giao bán một số lượng hữu hạn các tín chỉ, giấy phép phát thải một lượng các-bon nhất định (thường được quy định là 1 tấn $\mathrm{CO}_{2}$ tđ) trong một khoảng thời gian. Bên phát thải chỉ có quyền phát thải tương đương với số lượng tín chỉ hoặc giấy phép đang sở hữu. Các doanh nghiệp phát thải có nguyện vọng tăng lượng phát thải, tương ứng tăng lượng sản xuất, sẽ phải mua tín chỉ từ những bên có nguyện vọng bán lại. Theo đó, bên mua sẽ phải trả các chi phí phát sinh do tăng mức phát thải, ngược lại bên bán sẽ được hưởng lợi từ cắt giảm phát thải khí nhà kính. Vì vậy, các bên có khả năng giảm phát thải hiệu quả sẽ có động lực để thực sự tiến hành giảm phát thải và qua đó thúc đẩy động lực đầu tư vào công nghệ sạch, ít phát thải. Thị trường các-bon tự nguyện hoạt động bên lề thị trường bắt buộc, và hỗ trợ các doanh nghiệp, cá nhân mua và bán tín chỉ các-bon theo cơ chế tự nguyện. Một số tiêu chuẩn trong thị trường các-bon tự nguyện như: Tiêu chuẩn các-bon chứng nhận (VCS), Tiêu chuẩn vàng (GS)... Điểm đặc biệt của thị trường các-bon tự nguyện là sự đa dạng của các dự án của các bên, và thường được coi là nơi thử nghiệm trước khi đưa vào thị trường các-bon bắt buộc.

Xây dựng thị trường trao đổi tín chỉ các-bon là một hoạt động mang tính đặc thù, do một tổ chức chính quyền sử dụng các công cụ chính sách dựa trên tiềm năng và mục tiêu giảm phát thải của một cộng đồng, một khu vực, một tỉnh, một thành phố, một quốc gia hay thậm chí một thị trường toàn cầu và hướng đến một nền kinh tế ít phát thải, bền vững hơn. Hiểu được tầm quan trọng của thị trường các-bon trong ứng phó với biến đổi khí hậu, nhiều nghiên cứu trên thế giới đã và đang được tiến hành. Theo đánh giá, thị trường các-bon vẫn đang trong giai đoạn sơ khai, chưa đạt được độ chín muồi [3]. Tuy nhiên, tiềm năng phát triển thị trường các-bon toàn cầu được đánh giá là vô cùng lớn, có tiềm năng phát triển và giá trị giao dịch đạt mốc hàng trăm tỷ Đô la Mỹ một năm [4]. Tuy nhiên, hiệu quả của thị trường các-bon chưa được đánh giá một cách chi tiết, cụ thể [5] và để có thể đạt được hiệu quả hướng đến, cần những thỏa thuận, quy định luật pháp rõ ràng từ phía Chính phủ hoặc liên Chính phủ [6]. Theo đó, các bên tham gia giao dịch hay các tổ chức phi chính phủ không có đủ sức mạnh chính trị cần thiết để thiết lập, quản lý và phát triển thị trường.

Kinh nghiệm quốc tế là rất nhiều, cả cơ sở khoa học hàn lâm lẫn cơ sở thực tiễn của các thị trường đã hình thành lâu đời từ những năm 2003 tại các quốc gia phát triển hoặc những thị trường mới hình thành gần đây nhưng có kế thừa kinh nghiệm tại các quốc gia đang phát triển. Tuy nhiên do đặc thù mỗi quốc gia có mức độ phát triển kinh tế khác nhau, cũng như có đặc thù văn hóa xã hội khác biệt nên thị trường các-bon là không thể sao chép. Chính vì vậy, cần chọn lọc các kinh nghiệm quốc tế về các nội dung liên quan đến thị trường các-bon, các kiến thức và thông tin phải rất tổng hợp nhưng cô đọng và phù hợp hoàn cảnh tại Việt Nam.

\section{Phương pháp nghiên cứu}

Việc nghiên cứu kinh nghiệm quốc tế nhằm đề xuất chính sách để xây dựng thị trường trao đổi tín chỉ các-bon được thực hiện thông qua các bước sau:

Bước 1: Rà soát, phân tích văn bản liên quan và tình hình triển khai thị trường các-bon của một số nước và tổ chức quốc tế như: Liên minh châu Âu, New Zealand, Trung Quốc, Thái Lan.

Các văn bản được rà soát và phân tích bao gồm: các văn bản pháp luật của các nước quy định về thị trường các-bon, báo cáo của UNFCCC về các Bên tham gia UNFCCC, Nghị định thư Kyoto, Thỏa thuận Paris, phát thải khí nhà kính, báo cáo của World Bank, International Carbon Partnership.

Bước 2: Xác định cơ sở thực tiễn.

Dựa trên mục tiêu cắt giảm khí nhà kính toàn cầu và những quy định về thị trường, đặc biệt là thị trường các-bon trong khuôn khổ UNFCCC; thực tiễn triển khai thị trường các-bon quốc 
tế, thị trường các-bon tự nguyện và thị trường các-bon nội địa đang vận hành tại nhiều quốc gia, vùng lãnh thổ trên thế giới như Liên minh châu Âu, Thái Lan, New Zealand, Trung Quốc và thực tiễn tại Việt Nam với mục tiêu đến năm 2030 sẽ giảm $9 \%$ tồng lượng phát thải khí nhà kính so với kịch bản phát triển thông thường. Tuy nhiên, song song với các nỗ lực giảm nhẹ, Chính phủ Việt Nam cũng đặt ưu tiên trong việc duy trì đà phát triển kinh tế-xã hội. Trong bối cảnh như vậy, việc đánh giá vai trò và tầm quan trọng của thị trường các-bon nội địa hỗ trợ thực hiện NDC của Việt Nam cũng như việc xây dựng thiết lập mô hình thị trường các-bon phù hợp với điều kiện chính trị, kinh tế, xã hội là phù hợp và thiết thực.

Bước 3: Tham vấn các chuyên gia

Tiến hành tham vấn các đơn vị, chuyên gia tư vấn có nhiều năm kinh nghiệm về triển khai các cơ chế tạo tín chỉ như CDM, JCM và các hoạt động tạo tín chỉ khác tại Việt Nam về các khó khăn trong triển khai thị trường các-bon tại Việt Nam.

Bước 4: Tổng hợp và phân tích

Tổng hợp và phân tích các kết quả rà soát chính sách và tham vấn các bên liên quan, để từ đó đề xuất các bài học phù hợp cho Việt Nam.

\section{Kết quả và thảo luận}

\subsection{Kinh nghiệm quốc tế trong xây dụng thị trường các-bon}

\subsubsection{Châu Âu}

Thị trường các-bon của Liên minh châu Âu (European Union Emission Trading Scheme/ $E U-E T S)$, vận hành từ năm 2005 , là thị trường thương mại phát thải quốc tế đầu tiên và là một trong các công cụ chính sách quan trọng nhất của Liên minh châu Âu để ứng phó với BĐKH, thực thi cam kết trong Nghị định thư Kyoto trước đây và sau này là Thỏa thuận Paris về biến đổi khí hậu. Trải qua 3 thời kỳ sửa đổi và điều chỉnh, hiện nay ở giai đoạn 3 , đây là thị trường trao đổi phát thải các-bon chính và lớn nhất thế giới với toàn bộ 28 quốc gia thành viên Châu Âu và 3 nước trong khu vực tham gia, giới hạn phát thải từ hơn 11.000 doanh nghiệp sử dụng nhiều năng lượng (tập trung vào các nhà máy sản xuất năng lượng, nhà máy sản xuất công nghiệp sử dụng nhiều năng lượng như sắt thép, xi măng, gốm, giấy và ngành hàng không). Lượng phát thải trao đổi trên thị trường chiếm khoảng $45 \%$ tổng lượng phát thải toàn châu Âu và khoảng $3 / 4$ thị trường phát thải các-bon toàn cầu. Quy mô và phạm vi các ngành chi tiết của thị trường cácbon châu Âu các giai đoạn được thể hiện trong Hình 1.

Nguyên lý hoạt động của EU-ETS là theo nguyên tắc hạn mức và thương mại (cap-andtrade). Theo đó, các hạn mức tuyệt đối về số lượng phát thải khí nhà kính được thiết lập và giảm dần theo thời gian. Các tổ chức, doanh nghiệp được phân phối hoặc mua các tín chỉ, giấy phép phát thải qua cơ chế đấu giá, đồng thời có thể giao dịch với nhau nếu cần thiết. Thị trường cho phép mua bán, trao đổi tín chỉ với các dự án giảm phát thải quốc tế khác, ví dụ các dự án thuộc Cơ chế phát triển sạch CDM. Với việc đặt hạn mức về lượng phát thải, các tín chỉ hoặc giấy phép trở nên có giá trị và trao đổi được trên thị trường. Trường hợp phát thải quá hạn mức được phép, các công ty và tổ chức được châu Âu quy định mức phạt chung là 100 EUR/tấn $\mathrm{CO}_{2}[8]$. Danh sách các tổ chức vi phạm cũng sẽ được công bố hằng năm. 


\begin{tabular}{|c|c|c|c|}
\hline Nội dung & Pha 1 (2005-2007) & Pha 2 (2008-2012) & Pha 3 (2013-2020) \\
\hline $\begin{array}{l}\text { Qui mô/ Đặc điểm } \\
\text { địa lý }\end{array}$ & EU27 & $\begin{array}{c}\text { EU27 + Nauy, Iceland } \\
\text { Liechtenstein }\end{array}$ & EU27+3 \\
\hline Phạm vi/ Lĩnh vực & $\begin{array}{l}\text { Nhà máy điện } \geq 20 M W \\
\text { Lọc dầu } \\
\text { Lò luyện than cốc } \\
\text { Nhà máy sắt, thép } \\
\text { Xi măng clinker } \\
\text { Thủy tinh } \\
\text { Vôi, Gạch, Đồ sứ } \\
\text { Bột giấy, Giấy và bìa }\end{array}$ & $\begin{array}{l}\text { Các lĩnh vực ở pha I thêm } \\
\text { ngành hàng không (từ năm } \\
\text { 2012) }\end{array}$ & $\begin{array}{l}\text { Các lĩnh vực ở pha I thêm luyện Nhôm } \\
\text { Lọc dầu, Hàng không (hiệu lực từ 1.1.2014), } \\
\text { Sản xuất Ammonia ; Sản xuât axit nitric, adipic } \\
\text { và glyoxylic; Thu hồi CO2, chuyển theo ống } \\
\text { dẫn và lưu giữ CO2 }\end{array}$ \\
\hline Lượng trần phát thải & & & Áp dụng mức trần phát thải trên toàn EU \\
\hline Loại KNK & $\mathrm{CO} 2$ & CO2, N2O (có chọn lựa) & CO2, N2O, PFC từ sản xuất nhôm \\
\hline $\begin{array}{l}\text { Đơn vị cho phép } \\
\text { giao dịch }\end{array}$ & EUAs & $\begin{array}{l}\text { EUAs, CERs, ERUs } \\
\text { Không bao gồm: tín chỉ từ rừng, } \\
\text { và các dự án thủy điện lớn. }\end{array}$ & $\begin{array}{l}\text { EUAs, CERs, ERUs } \\
\text { Không bao gồm: CERs và ERUs từ rừng, HFC, } \\
\text { N2O hoặc các dự án thưy điện lớn. Lưu ý: } \\
\text { CERs từ các dự án đăng ký sau năm } 2012 \text { phải } \\
\text { từ danh sách Các nước kém phát triển nhất }\end{array}$ \\
\hline Phân phối tín chỉ & $\begin{array}{l}\text { Phân bổ tự do. Lượng t } \\
\text { định theo NAPs do từng } \\
\text { Ủy ban EU phê duyệt d } \\
\text { thải trong quá khi }\end{array}$ & $\begin{array}{l}\text { tín chỉ được phân bổ được quyết } \\
\text { quốc gia thành viên tự đề xuất và } \\
\text { lựa trên phương pháp mức phát } \\
\text { ư (grandfathering method) }\end{array}$ & $\begin{array}{l}\text { Đấu giá hoàn toàn các tín chỉ liên quan đến lĩnh } \\
\text { vực năng lượng, tín chỉ ngành công nghiệp } \\
\text { được phân bổ tự do sử dụng phương pháp } \\
\text { ngưỡng tiêu thụ (benchmarking method) }\end{array}$ \\
\hline
\end{tabular}

Hình 1. Quy mô và phạm vi thị trường các-bon châu Âu [7].

\subsubsection{New Zealand}

Thị trường các-bon New Zealand (NZ-ETS) chính thức hoạt động từ năm 2008 và bao gồm hầu hết các lĩnh vực trong nền kinh tế. Chính phủ New Zealand đã hai lần tiến hành rà soát và điều chỉnh thị trường. Lần thứ nhất vào năm 2011 [9] và lần thứ hai được tiến hành vào năm 2015 và kết thúc vào năm 2017 [10]. Điểm đặc biệt của thị trường là bao gồm cả lĩnh vực lâm nghiệp, lĩnh vực chủ yếu hấp thụ khí nhà kính thay vì phát thải. Phương thức vận hành thị trường cũng tuân theo phương thức hạn mức và thương mại. Các tín chỉ hoặc giấy phép phát thải sẽ được phân bổ miễn phí hoặc theo cơ chế đấu giá. Chính phủ New Zealand yêu cầu tất cả các ngành phải báo cáo lượng phát thải hằng năm để mua hoặc nộp lại theo hạn mức chính phủ đề ra. Ngoài ra, Chính phủ New Zealand cũng áp dụng các mức phạt cho các tổ chức không hoàn thành nghĩ vụ về thu thập số liệu hoặc cố tình chỉnh sửa sai sót thông tin báo cáo. Đồng thời, trong giai đoạn đầu, thị trường trao đổi phát thải được xây dựng để liên kết với thị trường cácbon quốc tế theo Nghị định thư Kyoto. Tuy nhiên bắt đầu từ năm 2015, Chính phủ New Zealand chỉ tập trung vào thị trường nội địa và các tín chỉ theo thị trường quốc tế sẽ không được công nhận. Tính đến năm 2019, đã có hơn 2.360 tổ chức và doanh nghiệp đăng ký, chiếm khoảng 52\% tổng lượng phát thải toàn quốc gia. Ngoài ra, chính phủ New Zealand cũng ban hành cơ chế giá sàn, với mức giá $25 \mathrm{NZD}$ cố định cho thị trường các-bon [11].

Là một trong những quốc gia đầu tiên trên thế giới triển khai thị trường các-bon, New Zealand cũng đã đạt được những thành tựu nhất định trong giảm phát thải khí nhà kính và thúc đẩy đầu tư công nghệ phát triển các-bon thấp. Tuy nhiên, mô hình thị trường các-bon của New Zealand vẫn còn nhiều hạn chế nhất định. Việc thiếu vắng hạn mức chung cho toàn quốc gia gây ảnh hưởng đến việc đạt được các mục tiêu giảm phát thải. Cơ chế giá sàn cố định mặc dù được coi là cơ chế bình ổn thị trường tốt, đã tạo rào cản cho các doanh nghiệp muốn thu hút thêm đầu tư và qua đó ảnh hưởng đến hiệu quả của thị trường các-bon.

\subsubsection{Trung Quốc}

Năm 2011, Chính phủ Trung Quốc đã ban hành Kế hoạch phát triển kinh tế xã hội 5 năm lần thứ 12 cho giai đoạn 2011-2015 [12]. Trong đó, kế hoạch xây dựng một thị trường các-bon trong tương lai đã được đề cập. Trong các năm tiếp theo, một loạt các thị trường các-bon thí 
điểm đã được triển khai tại cấp thành phố và cấp tỉnh (Thượng Hải, Bắc Kinh, Quảng Đông, Thiên Tân, Hồ Bắc, Trùng Khánh và Phúc Kiến). Đến năm 2017, Trung Quốc chính thức ban hành Chương trình thiết lập thị trường các-bon quốc gia, dự kiến chính thức đi vào hoạt động vào năm 2020. Thị trường trao đổi các-bon của Trung Quốc sẽ tập trung vào lĩnh vực năng lượng, chiếm $1 / 3$ lượng phát thải toàn quốc gia tương đương 3,5 tỷ tấn $\mathrm{CO}_{2}$ và sẽ trở thành thị trường các-bon lớn nhất thế giới khi đi vào hoạt động. Trao đồi các-bon tại các lĩnh vực khác sẽ dự kiến triển khai sau năm 2020 [13].

Trong giai đoạn thí điểm, chính phủ Trung quốc định hướng triển khai hệ thống ETS tại những vùng tương đối phát triển về kinh tế với cường độ phát thải thấp hơn so với mức trung bình quốc gia [14]. Tuy nhiên, đây cũng là những nơi đông dân cư, có những sự khác biệt nhất định về kinh tế, GDP và cường độ phát thải (Bảng 1) Các tỉnh, thành phố được chọn triển khai thí điểm vào năm 2013 đều là những vùng có thu nhập vừa và cao, hơn mức thu nhập trung bình của quốc giá (Trùng Khánh và Hồ Bắc là ngoại lệ). Trong khi đó, cường độ phát thải của các vùng thấp hơn mức trung bình quốc gia, dù có sự khác biệt lớn giữa Thẩm Quyến và Hồ Bắc $\left(1,4 \mathrm{tCO}_{2} / \mathrm{usd}\right.$ và $\left.0,6 \mathrm{tCO}_{2} / \mathrm{usd}\right)$. Phát thải bình quân đầu người của các tỉnh và thành phố cũng có sự chênh lệch, dao động từ 4,4 lên 10,3 (mức bình quân quốc gia là 6,7).

Bảng 1. Thông tin các khu vực thí điểm thị trường các-bon tại Trung Quốc [14].

\begin{tabular}{lcccccc}
\hline Khu vực & $\begin{array}{c}\text { Dân số } \\
\text { (triệu người) }\end{array}$ & $\begin{array}{c}\text { GDP } \\
\text { (tỷ USD) }\end{array}$ & $\begin{array}{c}\text { Tổng phát } \\
\text { thải } \\
\text { (triệu tấn) }\end{array}$ & $\begin{array}{c}\text { GDP bình } \\
\text { quân đầu } \\
\text { người }\end{array}$ & $\begin{array}{c}\text { Phát thải } \\
\text { bình quân } \\
\text { đầu người }\end{array}$ & $\begin{array}{c}\text { Cường độ̣ } \\
\text { phát thải } \\
\text { (tCO2/ tỷ } \\
\text { USD) }\end{array}$ \\
\hline Trung quốc & 1137 & 5933 & 8900 & 4,4 & 6,7 & 1,5 \\
Bắc Kinh & 19,6 & 208 & 157 & 10,6 & 8,0 & 0,8 \\
Thiên Tân & 13,0 & 136 & 133 & 10,5 & 10,3 & 1,0 \\
Thượng Hải & 23,0 & 254 & 219 & 11,0 & 9,5 & 0,9 \\
Trùng Khánh & 28,9 & 117 & 168 & 4,1 & 5,8 & 1,4 \\
Hồ Bắc & 57,2 & 236 & 250 & 4,4 & 4,4 & 1,1 \\
Quảng Đông & 104,3 & 680 & 522 & 5,0 & 5,5 & 0,8 \\
Thâm Quyến & 10,4 & 140 & 84 & 13,5 & 8,1 & 0,6 \\
\hline
\end{tabular}

Điểm khác biệt lớn nhất của thị trường các-bon Trung Quốc đó là tiến hành thí điểm trên diện rộng tại các khu vực, thành phố với các mức độ kinh tế đa dạng khác nhau. Điều này cho phép chính phủ Trung Quốc thử nghiệm và đánh giá hiệu quả nhiều giải pháp quản lý thị trường khác nhau trong cùng một thời điểm. Có thể nói, Trung quốc vẫn đang ở trong giai đoạn đầu xây dựng và triển khai thị trường các-bon. Các thành tựu, kết quả hiện tại chủ yếu đến từ các kinh nghiệm, bài học có được thông qua việc tham gia Cơ chế phát triển sạch $\mathrm{CDM}$, và cam kết mạnh mẽ của chính phủ trong ứng phó với biến đổi khí hậu. Mặc dù các hệ thống ETS thí điểm có thể chưa mang lại các hiệu quả lớn về tiết kiệm năng lượng hay giảm phát thải khí nhà kính, nhưng với những bài học, thách thức trong xây dựng và vận hành sẽ hỗ trợ chính phủ Trung Quốc giảm thiểu rủi ro trong tương lai [15]. Việc lựa chọn thí điểm ETS trước khi áp dụng toàn quốc cũng được đánh giá là phù hợp với khái niệm quản lý chính sách vĩ mô của Trung Quốc cũng như của Việt Nam.

\subsubsection{Thái Lan}

Là một quốc gia có rất nhiều nét tương đồng với Việt Nam, Thái Lan là đất nước chúng ta cần tìm hiều và học tập các kinh nghiệm về thị trường các-bon. Kế hoạch kinh tế và phát triển quốc gia lần thứ 12 (2017-2021) của chính phủ Thái Lan đã đưa ra các giải pháp giảm phát thải khí nhà kính, trong đó gồm xây dựng thị trường các-bon nội địa [16]. Kế hoạch tổng thể biến đổi khí hậu quốc gia (2015-2050) cũng đề cập đến thị trường các-bon như một cơ chế tiềm năng trong giảm phát thải khí nhà kính trong khu vực tư nhân [17]. NDC của Thái Lan cũng nhấn mạnh tầm quan trọng của cơ chế thị trường, cụ thể là xây dựng và triển khai thị trường các-bon [18]. Từ 2013-2016, cơ quan Quản lý khí nhà kính Thái Lan (TGO) đã xây dựng hệ thống Đo đạc-Báo cáo-Thẩm đỉnh (MRV) cho thị trường các-bon tự nguyện của Thái Lan (Thailand V- 
ETS). Từ 2013-2014, xây dựng hướng dẫn chúng cho MRV cho V-ETS. Từ tháng 10/2014 đến tháng 9/2017, Thái Lan tiến hành thí điểm hệ thống V-ETS [19]. Mục tiêu trong giai đoạn đầu thí điểm là kiểm tra hệ thống $\mathrm{MRV}$, xây dựng hướng dẫn $\mathrm{MRV}$ cấp ngành và thiết lập hạn mức phát thải và phân bổ tín chỉ cho các nhà máy thuộc hệ thống. Giai đoạn thí điểm thứ hai từ 2018 đến 2020 sẽ tiến hành thí điểm hệ thống đăng ký và giao dịch tín chỉ. Chính phủ Thái Lan cũng đề cập đến cơ chế thị trường khuyến khích sự tham gia của khu vực tư nhân trong giảm nhẹ phát thải khí nhà kính trong Kế hoạch cải cách quốc gia. Chi tiết cụ thể sẽ được đề xuất trong Đạo luật biến đổi khí hậu, có hiệu lực vào năm 2020.

Mặc dù vẫn đang được phát triển, Thái Lan cho thấy sự kết hợp thú vị của các công cụ thị trường được liên kết, phù hợp với các lĩnh vực khác nhau, với hệ thống giao dịch phát thải cho ngành điện và các ngành sử dụng nhiều năng lượng, và các cơ chế bù đắp và chứng nhận hiệu quả năng lượng cho các ngành mà ETS sẽ là thử thách. Mối quan tâm về những hạn chế đối với tăng trưởng đã dẫn đến việc áp dụng các mục tiêu tương đối chủ yếu. Bên cạnh đó, việc thử nghiệm hệ thống ETS với những nền tảng cơ bản để thị trường từ điều tiết và chấp nhận hoạt động của các thành phần thị trường là những bước đi thận trọng cần thiết của Thái Lan thời gian qua. Hiện nay, các cơ sở nền tảng của hệ thống ETS được các doanh nghiệp tự nguyện đăng ký tham gia sẽ giúp cho việc hoàn thiện chính sách bảo vệ môi trường và tìm ra công cụ định giá các-bon thích hợp với cơ quan quản lý nhà nước của Thái Lan [20].

Kế hoạch chi tiết thực hiện và triển khai Chương trình V-ETS của Thái Lan trải qua các giai đoạn như sau: (1) Năm 2010: Tập trung nghiên cứu báo cáo khí nhà kính và $M R V$, tiềm năng giảm phát thải; (2) Năm 2011: Nghiên cứu và xác định các ngành công nghiệp; cách tiếp cận quy định mức trần và phân bổ cho phép; (3) Năm 2012: Nghiên cứu và đề xuất khung thề chế, nguyên tắc hoạt động, khuyến khích các hoạt động trao đổi phát thải tự nguyện; (4) Năm 20132014: Phát triển hệ thống MRV; nghiên cứu các nguyên tắc báo cáo khí nhà kính và khả năng kết nối; (5) Năm 2015: Nghiên cứu đánh giá tác động của hệ thống ETS và đánh giá tác động của biến đổi khí hậu; (6) Năm 2018-2020: Cải thiện và phát triển các nguyên tắc hoạt động, bao gồm cả hệ thống đăng ký và đề xuất lộ trình và kiến nghị về chính sách.

\section{2. Đề xuất}

Một quốc gia đang phát triển như Việt Nam được cho là có sự hình thành của thị trường các-bon là khi đã thiết lập một hệ thống giao dịch hạn ngạch phát thải khí nhà kính, tín chỉ cácbon và việc điều tiết của thị trường đó cần đảm bảo tính toàn vẹn môi trường và tính hiệu quả kinh tế. Thông qua nghiên cứu thị trường các-bon tại một số khu vực và quốc gia trên thế giới, có thể rút ra được một số bài học cho Việt Nam về bốn khía cạnh chính của thị trường: (i) Chính sách; (ii) Phạm vi và quy mô; (iii) Tổ chức và vận hành thị trường; và (iv) Hệ thống đo đạc, báo cáo, thẩm định $(\mathrm{MRV})$.

\subsubsection{Chính sách}

Việt Nam đã xây dựng và hoàn thiện nhiều văn bản quy phạm pháp luật để thực hiện các chính sách về bảo vệ môi trường, có liên quan đến biến đổi khí hậu hay liên quan đến thị trường như pháp luật về bảo vệ môi trường, pháp luật về khai thác tài nguyên, pháp luật về tiết kiệm năng lượng và sử dụng năng lượng hiệu quả, pháp luật về thuế nhiên liệu hay phí bảo vệ môi trường... Trên phương diện quốc tế, Việt Nam cũng là một quốc gia tích cực tham gia đàm phán, tham gia các điều ước quốc tế về khí hậu như Nghị định thư Kyoto, Thỏa thuận Paris, góp phần vào nỗ lực ứng phó với biến đổi khí hậu toàn cầu. Chính phủ Việt Nam đã ban hành một số Quyết định, Thông tư hướng dẫn liên quan đến các cơ chế trao đổi tín chỉ song phương và đa phương như Cơ chế tín chỉ chung (JCM) hay Cơ chế phát triển sạch (CDM). Tuy nhiên, Việt Nam chưa có văn bản pháp luật cụ thể riêng biệt dành riêng cho thị trường các-bon nội địa.

Dựa trên kinh nghiệm các nước, để xây dựng và vận hành thị trường các-bon nội địa, cần ban hành văn bản pháp lý có giá trị hiệu lực ở cấp cao, ví dụ như các đạo luật về thị trường cácbon ở Liên minh châu Âu, New Zealand, hay được thể hiện qua văn bản quy hoạch tầm vĩ mô như Kế hoạch phát triển kinh tế xã hội của Trung Quốc. Thái Lan cũng dự kiến đưa các nội dung 
về thị trường các-bon vào Luật Biến đổi khí hậu của quốc gia. Vì vậy, để tạo cơ sở xây dựng thị trường các-bon của Việt Nam, cần có quy định chi tiết hơn về thị trường các-bon trong Luật Bảo vệ Môi trường hiện nay (điểm đ khoản 1 Điều 41), cụ thể là Nghị định về thị trường cácbon tại Việt Nam. Đối với từng lĩnh vực cụ thể, cũng cần đưa ra những yêu cầu giảm phát thải khí nhà kính từ các nguồn phát thải trong các lĩnh vực năng lượng, công nghiệp, nông nghiệp, quản lý chất thải vào các chương trình hành động, chiến lược, quy hoạch, kế hoạch của các ngành/ lĩnh vực từ Trung ương đến địa phương; tiến tới áp dụng bắt buộc tiêu chí giảm phát thải khí nhà kính khi thẩm định, phê duyệt các chương trình, nhiệm vụ, dự án phát triển trong các ngành/ lĩnh vực.

\subsubsection{Phạm vi và quy mô}

Thị trường các-bon với quy mô và phạm vi rộng và phức tạp thường sẽ mang lại nhiều hiệu quả hơn nhưng đồng thời đòi hỏi sự chuẩn bị và cơ sở pháp lý, kỹ thuật chi tiết hơn. Việt Nam cần cân nhắc về mức độ quy mô ở giai đoạn ban đầu khi thiết lập thị trường, có thể thí điểm ở quy mô ngành (như Liên minh châu Âu) hoặc dạng tự nguyện (như Thái Lan), hoặc cơ chế cấp địa phương (như Trung Quốc). Khi xem xét phạm vi thị trường của Việt Nam, cần cân nhắc cả năm yếu tố cấu thành thị trường các-bon theo Hình 2.

Xuất phát điểm Kết quả mong muốn

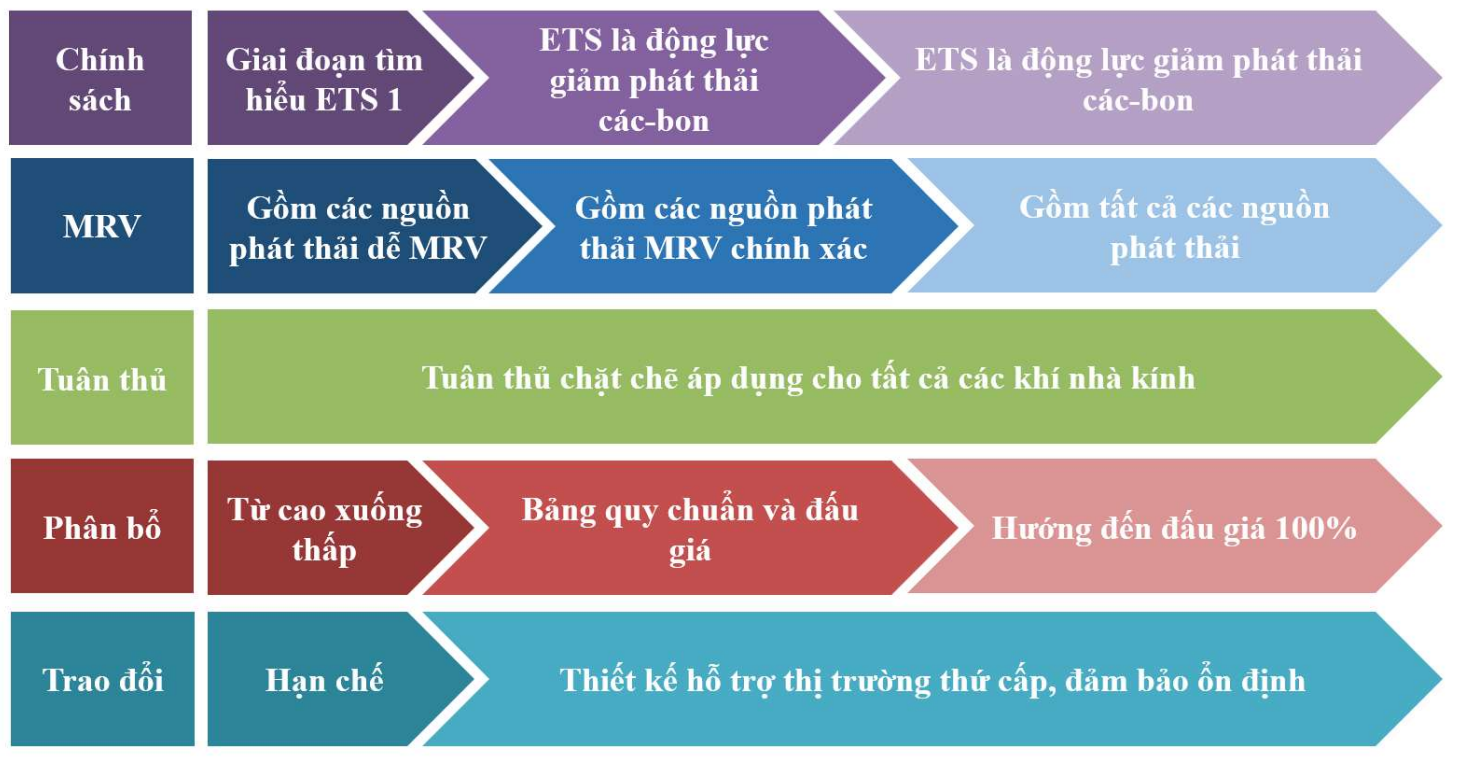

Hình 2. Các yếu tố cấu thành thị trường các-bon.

Mức độ về phạm vi và quy mô của thị trường phụ thuộc vào hiện trạng về chính sách, kinh nghiệm và hệ thống MRV đang có của Việt Nam. Với các yếu tố gần như ở mức sơ khai, Việt Nam cần có các giai đoạn ban đầu tìm hiểu nhu cầu thị trường. Theo đó, cấu trúc thị trường có thể đi từ cấp độ đơn giản đến các kế hoạch với cấu trúc phức tạp hơn khi mức độ sẵn sàng tham gia thị trường của các bên tăng lên. Các nước đang phát triển bao gồm Việt Nam có thể thực hiện các chính sách đơn giản hóa khi mức độ sẵn sàng tham gia giao dịch là thấp và tăng dần lên các hệ thống phức tạp hơn theo thời gian.

Mặc dù quy mô của hệ thống trao đổi tín chỉ các-bon ở Việt Nam không thể so sánh được với Trung Quốc hay không thể phát triển đồ sộ và chi tiết ngay như thị trường Liên minh châu Âu và có tính liên lĩnh vực như thị trường New Zealand, nhưng những thách thức và các giải pháp tiềm năng khác có thể phù hợp với các hoạch định chính sách của Việt Nam và Việt Nam hoàn toàn có thể học tập bước đi phát triển của các nước và đưa ra một lộ trình thí điểm ban đầu. Cụ thể, có thể tiến hành cho phép giao dịch thí điểm trong một ngành (ví dụ như ngành thép, ngành xi măng, ngành sản xuất điện, ngành chất thải...), với quan điểm bổ sung thêm các ngành 
khác ở giai đoạn sau, hoặc có thể thí điểm tại một số thành phố, khu vực có hoạt động kinh tế phát triển mạnh (ví dụ như Hà Nội, hoặc đồng bằng sông Cửu Long) và dần dần mở rộng quy mô của thị trường.

\subsubsection{Tổ chức và vận hành thị trường}

Có nhiều bài học về quản lý nhà nước nhằm tạo cơ sở cho việc sẵn sàng giao dịch trên thị trường các-bon mà chúng ta có thể học được từ kinh nghiệm quốc tế khi xây dựng thị trường các-bon cho Việt Nam. Có nhiều kinh nghiệm về cách thức quản lý nhà nước với đối với vấn đề này Việt Nam có thể tham khảo như kinh nghiệm của Trung Quốc hay Thái Lan là hai quốc gia có hoàn cảnh tương đồng cũng đang thí điểm vận hành thị trường các-bon. Một thuận lợi khác của Việt Nam là đã có nhiều năm kinh nghiệm và hoạt động tích cực trong các cơ chế tạo tín chỉ song phương và đa phương như $\mathrm{JCM}$ và $\mathrm{CDM}$. Tuy nhiên, công tác quản lý nhà nước với hoạt động giao dịch tín chỉ các-bon như là một sản phẩm hàng hóa vô hình của thị trường các-bon là khá mới mẻ, với phạm vi rộng, đa ngành, nhiều lĩnh vực, quản lý thị trường thị các-bon cần sự tham gia từ cấp Trung ương đến cấp Bộ, ngành, địa phương.

Chính vì vậy, cần thiết lập một ủy ban quản lý ở cấp quốc gia với các đầu mối, thành viên từ các Bộ, ngành có liên quan. Ủy ban này sẽ có nhiệm vụ phê duyệt các phương pháp luận, danh mục doanh nghiệp tham gia thị trường và hạn mức phát thải phân bổ cho từng doanh nghiệp theo giai đoạn. Ủy ban này sẽ được hỗ trợ bởi các Ban Kỹ thuật và Ban Thư ký. Ban Kỹ thuật sẽ được thành lập với các thành viên là chuyên gia tư vấn kỹ thuật, có chuyên môn sâu về từng lĩnh vực trong thị trường. Nhiệm vụ của Ban Kỹ thuật đó là xây dựng các phương pháp luận, tính toán các mô hình phát thải của các ngành trong tương lai. Các tiểu ban kỹ thuật cũng có thể được thành lập cho các cấp thấp hơn thuộc các Bộ, ngành và địa phương, đây là nhiệm vụ rất cần thiết. Tại Việt Nam, hiện nay chưa hình thành chính thức các nhóm/ban kỹ thuật trực thuộc các Bộ, ngành. Ban Thư ký sẽ có nhiệm vụ hỗ trợ kỹ thuật, điều phối giữa các bên liên quan, đồng thời quản lý hệ thống cơ sở dữ liệu, đảm bảo sự thông suốt của thông tin, hỗ trợ Ủy ban quản lý đưa ra các quyết định.

\subsubsection{Hệ thống Đo đạc-Báo cáo-Thẩm định (MRV)}

Hệ thống MRV cần được xây dựng và thực hiện trong bất kỳ thị trường các-bon nào. Hệ thống MRV cũng được sử dụng rộng rãi trong các cơ chế, đề án giảm phát thải khí nhà kính trên toàn thế giới. Có thể coi xây dựng và triển khai thành công hệ thống MRV là bước đầu tiên để tiến tới hình thành thị trường các-bon nội địa (như trong trường hợp của Thái Lan). Các phương pháp đo lường và đánh giá lượng phát thải khí nhà kính của các hành động, dự án phải là một sản phẩm của cả một quy trình trong đó các quyết định chính trị đã được cam kết để tạo thành một khuôn khổ pháp lý cho các hoạt động giảm nhẹ nói chung và hệ thống MRV nói riêng.

Trước hết, cần xây dựng hệ thống MRV ở cấp quốc gia và cấp ngành/lĩnh vực phù hợp với điều kiện cụ thể của Việt Nam và quy định của UNFCCC. Để thiết lập và vận hành hệ thống MRV cần xây dựng quy định, quy trình đo đạc, báo cáo và thẩm định cụ thể, rõ ràng và phù hợp với điều kiện Việt Nam cho cấp quốc gia và các lĩnh vực: năng lượng, các quá trình công nghiệp, nông nghiệp, LULUCF và chất thải. Đồng thời cần thành lập cơ cấu tổ chức và cơ chế vận hành MRV, có nghĩa là đưa ra các chức năng, nhiệm vụ cụ thể của các cơ quan Chính phủ, địa phương về các hoạt động đo đạc, báo cáo và thẩm định. Các hoạt động này có mối liên kết không thể tách biệt, trong đó đo đạc là một điều kiện tiên quyết cho quá trình báo cáo và thẩm định.

Hệ thống MRV cấp quốc gia sẽ dựa trên phương pháp tiếp cận theo hướng từ trên xuống cho mục tiêu giảm nhẹ quốc gia và cần được thể hiện ở văn bản pháp lý tầm quốc gia như Nghị định và Quyết định của Thủ tướng Chính phủ. Trong khi đó, đề xuất MRV cấp ngành sẽ dựa trên phương pháp tiếp cận từ dưới lên mà không phụ thuộc nhiều vào hệ thống thu thập dữ liệu tập trung. Những hệ thống MRV cấp ngành sẽ hướng dẫn đo lường ở cấp độ dự án hoặc cấp ngành. Việc phân cấp các cách tiếp cận cũng đem lại những lợi ích thiết thực. Lĩnh vực nào sớm xây dựng và triển khai hệ thống MRV thì sớm được tham gia thị trường. Hơn nữa, năng lực giám sát, báo cáo và thẩm định các hành động giảm nhẹ phát thải khí nhà kính có thể được học hỏi từ 
các kinh nghiệm hiện có như CDM, JCM, hoặc tiêu chuẩn ISO trong quản lý môi trường và năng lượng mà áp dụng phổ biến ở Việt Nam.

\section{Kết luận}

Từ cơ sở pháp lý đến giai đoạn triển khai thực hiện, các khu vực và quốc gia đều cần khoanh vùng xác định phạm vi và quy mô thị trường để từ đó có được có sự phối hợp giữa các Bộ, ngành liên quan. Đồng thời, việc xây dựng và triển khai thành công hệ thống MRV được coi là cơ sở thực tiễn và là nền tảng để hình thành thị trường các-bon. Kinh nghiệm từ các nước là bài học rất quan trọng cho Việt Nam trong việc xây dựng và triển khai khung thị trường các-bon trong tương lai.

Việt Nam đã có cam kết mạnh mẽ đối với vấn đề phát triển bền vững và ứng phó với những thách thức của biến đổi khí hậu. Đây cũng là cơ hội để Việt Nam chuyển đổi mô hình phát triển kinh tế bền vững. Thông qua việc nghiên cứu tình hình khu vực và quốc gia trên thế giới, có thể thấy thị trường các-bon của các nước đều được các chính phủ coi là trụ cột trong chính sách giảm phát thải khí nhà kính. Cơ sở chính sách đều bắt nguồn từ các cam kết quốc tế và mục tiêu giảm phát thải quốc gia, được luật hóa, quy định thông qua các văn bản pháp luật quan trọng. Để thiết lập, vận hành thị trường các-bon nội địa, cần nghiên cứu ban hành các chính sách liên quan sau: (1) Nghị định về thị trường các-bon; (2) Quy định lộ trình, giải pháp để phát triển thị trường các-bon, bao gồm quy mô của thị trường; (3) Quy định về cơ cấu tổ chức, vận hành thị trường; (4) Quy định về hệ thống MRV cấp quốc gia, cấp ngành/lĩnh vực.

Đóng góp của tác giả: Xây dựng nghiên cứu ý tưởng: M.K.L., N.T.C.; Lựa chọn phương pháp nghiên cứu: M.K.L., Đ.T.A.; Xử lý số liêu: L.Q.H., N.T.C.; Viết bản thảo: N.T.C., Đ.T.A.; Chỉnh sửa báo cáo: M.K.L., L.Q.H.

Lời cảm ơn: Tập thể tác giả xin trân trọng cảm ơn Đề tài KHCN cấp quốc qia "Nghiên cứu đề xuất mô hình thị trường các-bon ở Việt Nam", thuộc Chương trình "Khoa học và công nghệ ứng phó với biến đổi khí hậu, quản lý tài nguyên và môi trường giai đoạn 2016-2020”, mã số BĐKH.40/16-20 đã hỗ trợ về số liệu và phương pháp luận để thực hiện bài báo này.

Lời cam đoan: Tập thể tác giả cam đoan bài báo này là công trình nghiên cứu của tập thể tác giả, chưa được công bố ở đâu, không được sao chép từ những nghiên cứu trước đây; không có sự tranh chấp lợi ích trong nhóm tác giả.

\section{Tài liệu tham khảo}

1. Stern Review. 2006. Trang online: http://www.hmtreasury.gov.uk/d/CLOSED_SHORT_executive_summary.pdf

2. World Bank. State and Trends of Carbon Pricing, 2020. Trang online: https://openknowledge.worldbank.org/bitstream/handle/10986/33809/9781464815867. pdf

3. Whittaker M. Global Climate Change: Uncovering Hidden Investment Risk and Opportunity. The Geneva Papers on Risk and Insurance 2000, 25, 619-628, https://www.jstor.org/stable/41952555.

4. Calel, R. Carbon markets: a historical overview. Wiley Interdiscip. Rev. Clim. Change 2013, 4, 107-119. https://doi.org/10.1002/wcc.208

5. Lane, R. The promiscuous history of market efficiency: the development of early emissions trading systems. Environ. Politics 2012, 21, 583-603. https://doi.org/10.1080/09644016.2012.688355.

6. Lederer, M. Market making via regulation: the role of state in carbon market. Regul. Governance 2012, 6, 524-544. https://doi.org/10.1111/j.1748-5991.2012.01145.x

7. EU Emission Trading System (EU-ETS). Trang online: https://ec.europa.eu/clima/policies/ets_en 
8. International Carbon Action Partnership. 2020. Trang online: https://icapcarbonaction.com/en/ets-map?etsid=43

9. Lần rà soát thứ nhất của New Zealand. Trang online: http://www.mfe.govt.nz/climatechange/new-zealand-emissions-trading-scheme/reviews-of-nz-ets/nz-ets-review2011

10. Lần rà soát thứ hai của New Zealand. Trang online: http://www.mfe.govt.nz/climatechange/new-zealand-emissions-trading-scheme/reviews-of-nz-ets/nz-ets-review201516/about-nz

11. International Carbon Action Partnership. 2020. Trang online: https://icapcarbonaction.com/en/ets-map?etsid $=48$

12. Kế hoạch phát triển kinh tế xã hội 5 năm lần thứ 12 của Trung quốc cho giai đoạn 20112015. Trang online: https://policy.asiapacificenergy.org/node/37

13. Chương trình thiết lập thị trường các bon quốc gia. 2019. Trang online: https://chinaenergyportal.org/en/national-carbon-emissions-trading-marketestablishment-program-power-generation-industry/

14. National Development and Reform Commission, China. Trang online: https://en.ndrc.gov.cn/

15. Hua, Y.; Dong, F. China's Carbon Market Development and Carbon Market Connection: A Literature Review. Energies 2019, 12, 1663. https://doi.org/10.3390/en12091663.

16. Kế hoạch kinh tế và phát triển quốc gia lần thứ 12 của Thái Lan cho giai đoạn $2017-$ 2021. Trang online: http://www.nesdb.go.th/nesdb_en/ewt_w3c/ewt_dl_link.php?nid=4345.

17. Kế hoạch tổng thể biến đổi khí hậu quốc gia của Thái Lan cho giai đoạn 2015-2050. Trang online: http://www.asialeds.org/resource/national-master-plan-on-climatechange-2011-2050-thailand/.

18. Đóng góp do quốc gia tự quyết định (NDC) của Thái Lan. Trang online: https://www4.unfecc.int/sites/ndestaging/PublishedDocuments/Thailand\%20First/Thai land_INDC.pdf

19. Thị trường các-bon tự nguyện của Thái Lan (Thailand V-ETS). Trang online: http://www.tgo.or.th/2020/index.php/en/page/thailand-v-ets-765.

20. Usapein, P.; Chavalparit, O. A start-up MRV system for an emission trading scheme in Thailand: A case study in the petrochemical industry. J. Cleaner Prod. 2017, 142, 33963408. https://doi.org/10.1016/j.jclepro.2016.10.127.

\title{
Carbon market: international experiences and policy proposal for Viet Nam
}

\author{
Mai Kim Lien', Luong Quang Huy ${ }^{1}$, Nguyen Thanh Cong ${ }^{1}$, Do Tien Anh ${ }^{2}$ \\ ${ }^{1}$ Department of Climate Change; lien_va21@yahoo.com, huylq98@gmail.com, \\ tcongnguyen90@gmail.com \\ ${ }^{2}$ Vietnam Meteorological and Hydrological Administration; atdo1980@gmail.com
}

\begin{abstract}
Viet Nam considers climate change a matter of survival. Viet Nam's response to climate change must be always associated with sustainable development towards a low-carbon economy. Accordingly, in the Nationally Determined Contribution (NDC), with domestic resources, by 2030, Viet Nam commits to reduce total greenhouse gas emissions by about $9 \%$ compared to the Business-As-Usual scenario, focusing on 5 main sectors: energy; waste; agriculture; land use, land use change, and forestry (LULUCF); and industrial processes. This contribution can be increased by up to $27 \%$ with international support through bilateral as well as multilateral cooperation and the implementation of new mechanisms under the Paris Agreement. Along with mitigation efforts, the Government of Viet Nam also places a priority
\end{abstract}


on maintaining the momentum of socio-economic development. In such a context, it is suitable and practical to develop and establish a domestic carbon market in accordance with the economic, political and social conditions of Viet Nam. However, in order to support the development of domestic carbon markets in Viet Nam, it is necessary to, first of all, study international experiences in carbon market formulation, and to understand the context of formulation, the goals and how the markets operate. The domestic carbon markets in different countries have different characteristics, the markets of developed countries are different from those of developing countries. Based on the synthesis of international experiences, analysis of the current state of institutional and policy infrastructure in Viet Nam, the article proposes specific solutions towards developing and successfully implementing the domestic carbon market for Viet Nam.

Keywords: Domestic carbon market; Nationally Determined Contribution; ETS. 